\title{
The mystery of angiographically silent macular oedema due to taxanes
}

\author{
Tatiana I. Kuznetcova • Petr Cech • \\ Carl P. Herbort
}

Received: 5 March 2012/Accepted: 23 March 2012/Published online: 8 April 2012

(C) Springer Science+Business Media B.V. 2012

\begin{abstract}
Taxanes are widely used anticancer agents, produced from the plants of the genus Taxus (yews). One of the rare side-effects caused by taxanes is a bilateral cystoid macular oedema (CMO). The particularity of this type of CMO is that it is angiographically silent showing no leakage or pooling on fluorescein angiography (FA). To date, the mechanism of this oedema has not been clearly understood and existing theories do not explain this phenomenon very well. Our aim was to report a case of paclitaxel-induced CMO and put forward a putative explanation for this occurrence. A 64-year-old woman presented with a 7-month history of progressively decreasing bilateral visual acuity with an apparently normal fundus. At entry her best-corrected visual acuity (BCVA) was 0.4 for far and near OD and 0.5 for far and near OS. Optical coherence tomography (OCT) revealed a CMO with a central thickness of
\end{abstract}

T. I. Kuznetcova $(\bowtie) \cdot$ C. P. Herbort

Centre for Ophthalmic Specialised Care (COS),

Rue de la Grotte 6, 1003 Lausanne, Switzerland

e-mail: brionika@gmail.com

T. I. Kuznetcova

Ophthalmology Department, I.P. Pavlov State Medical

University, Saint-Petersburg, Russia

P. Cech

Centre de Chimiothérapie Anti-Cancéreuse (CCAC),

Lausanne, Switzerland

C. P. Herbort

University of Lausanne, Lausanne, Switzerland
$561 \mu \mathrm{m}$ OD and $488 \mu \mathrm{m}$ OS; there were no signs of intraocular inflammation. FA showed no capillary leakage and quasi absent late hyperfluorescence OU. Indocyanine green angiography was within normal limits. Classical CMO treatment was ineffective and only discontinuation of paclitaxel resulted in recovery of a normal macular structure after 4 weeks with an increase of BCVA to $0.9 \mathrm{OD}$ and 1.0 OS. In order to understand the properties of taxane drug-induced cystoid macular oedema (TDICMO) we compared the spectral OCT findings of our case to an inflammationinduced CMO of equal thickness and to a case of multifocal choroiditis. The plane of separation of TDICMO was above the external limiting membrane in both cases. In contrast to inflammation-induced CMO where the four external bands were well identified, there was attenuation of these bands in TDICMO but no disruption of the layers as seen in multifocal choroiditis, indicating that the fluid in TDICMO had a high viscosity producing a shadow underneath. TDICMO most probably originates from retinal pigment epithelium dysfunction by their effect on microtubule functions and not from vascular leakage. The content of the CMO seems to be made up of viscous fluid. As the origin of the CMO is not inflammatory, classical CMO treatments have no effect and only discontinuation of the taxane drug allows reversal of the CMO.

Keywords Cystoid macular oedema Fluorescein angiography · Indocynine green angiography · Optical coherence tomography $\cdot$ Taxane drugs $\cdot$ Paclitaxel 


\section{Introduction}

Taxanes [paclitaxel $\left(\right.$ Taxol $\left.^{\circledR}\right)$, docetaxel $\left(\right.$ Taxotere $\left.^{\circledR}\right)$, and protein-bound paclitaxel (Abraxane ${ }^{\circledR}$ )] are widely used anticancer agents produced by the plants of the genus Taxus (yews) [1,2]. Their main mechanism of cytotoxic action is based on the stabilisation of microtubules leading to cell mitotic inhibition [2, 3].

Since the 1990s, fluid retention is a well-known adverse effect of the taxane group of drugs [4]. It is characterised by oedema, weight gain, and third-space fluid collection (pericardial, pleural, ascites) and appears to be related to the absolute cumulative dose of taxane drugs [5]. A significant increase of circulating lymphokine-activated killer cells has been reported. Behar et al. [4] pointed out excessive transcapillary filtration of proteins. Semb et al. [5] revealed a significant decrease in colloid osmotic pressure of plasma (COPpl) and interstitial fluid (COPint), haemoglobin, haematocrit, albumin, and total protein values, when a cumulative docetaxel dose reached $200 \mathrm{mg} / \mathrm{m}^{2}$. They suggested that a plasma volume increase was followed by enhanced fluid filtration to the interstitium. After a cumulative docetaxel dose of $500 \mathrm{mg} / \mathrm{m}^{2}$, it was noted that the COPpl continued to decrease significantly, but COPint remained unchanged despite a significant increase in mean body weight and oedema formation [5].

One of the rare side-effects induced by taxanes is a bilateral visual acuity decrease due to taxane druginduced cystoid macular oedema (TDICMO) [6, 7]. To date, the mechanism of TDICMO has not been clearly understood. The particularity of TDICMO is that it is angiographically silent as fluorescein angiography (FA) fails to show significant capillary leakage and quasi absent angiographically visible intra- or subretinal pooling on late frames. Very faint permeability of retinal vessels has been put forward as an explanation with a breakdown of the retinal blood-ocular barrier so minute that even a small fluorescein molecule cannot extrude or only minimally extrudes [6]. We doubt that 'microleakage' is the explanation for TDICMO and present a new case of paclitaxel-induced CMO and put forward a pathophysiological explanation.

\section{Case report}

A sixty-four-year old female patient presented to the centre for ophthalmic specialised care (COS) in
Lausanne, Switzerland in December 2010 with a 7-month history of progressively decreasing bilateral visual acuity and apparently normal fundus findings. She consulted for a second opinion as no explanation for the decreased vision could be found.

She had been operated for breast cancer T1 N0 M0 in 2008 and had been receiving adjuvant hormonotherapy. Since March 30th, 2010, she had received a combination of Taxol ${ }^{\circledR}$ (paclitaxel, cumulative dose $2741.12 \mathrm{mg} / \mathrm{m}^{2}$ ) and $\operatorname{Avastin}^{\circledR}$ (bevacizumab, 20,700 mg), as first-line chemotherapy for metastatic hormonoresistant disease. At the beginning of June 2010, 3 months after the initiation of Taxol ${ }^{\circledR}$ therapy she noticed bilateral blurred vision. Three months later she noticed decreased visual acuity for which her ophthalmologist had found no explanation, and finally was seen by us 7 months later.

At entry her best-corrected visual acuity (BCVA) was 0.4 for far and near OD and 0.5 for far and near OS. There was no anterior chamber flare OU, and laser flare photometry showed absence of subclinical inflammation $(5.2$ and $5.6 \mathrm{ph} / \mathrm{ms}$, respectively, for the right and left eyes, i.e., normal values). There was a slight bilateral cataract and computerised campimetry showed no significant visual field impairment. Spectral optical coherence tomography (OCT) (Heidelberg Engineering, Inc., Heidelberg, Germany) showed bilateral cystoid macular oedema with a central thickness of $561 \mu \mathrm{m}$ OD and $488 \mu \mathrm{m}$ OS with what appeared as areas of loss of photoreceptor outer segments but probably corresponded to signal attenuation in the areas of maximal oedema (Fig. 1).

FA showed no capillary leakage and very faint barely visible late fluorescence OU (Fig. 1, middle pictures). Indocyanine green angiography was within normal limits showing neither hypofluorescent areas indicating no hypoperfusion of the choriocapillaris nor diffuse hyperfluorescence indicating no choroidal hyperpermeability (Fig. 1, bottom pictures).

Classical treatment for CMO was introduced including Diamox ${ }^{\circledR}$ (acetazolamide, $250 \mathrm{mg} /$ day), nonsteroidal drops (indomethacin $0.1 \%, 6 \times$ daily), prednisolone acetate drops $1 \%$ (Pred Forte ${ }^{\circledR}, 3 \times$ daily) with no effect whatsoever after 5 weeks.

The CMO was then attributed to the Taxol ${ }^{\circledR}$ treatment and we asked her oncologist to discontinue this treatment. One month later the retinal macular structure had returned to a normal morphology with a central thickness of $225 \mu \mathrm{m}$ OD and $240 \mu \mathrm{m}$ OS and normal aspect of the four outer OCT bands (external 
Fig. 1 Bilateral cystoid macular oedema with a central thickness of $561 \mu \mathrm{m}$ OD and $488 \mu \mathrm{m}$ OS. FA shows no capillary leakage and very faint barely visible late fluorescence OU. Indocyanine green angiography is within normal limits

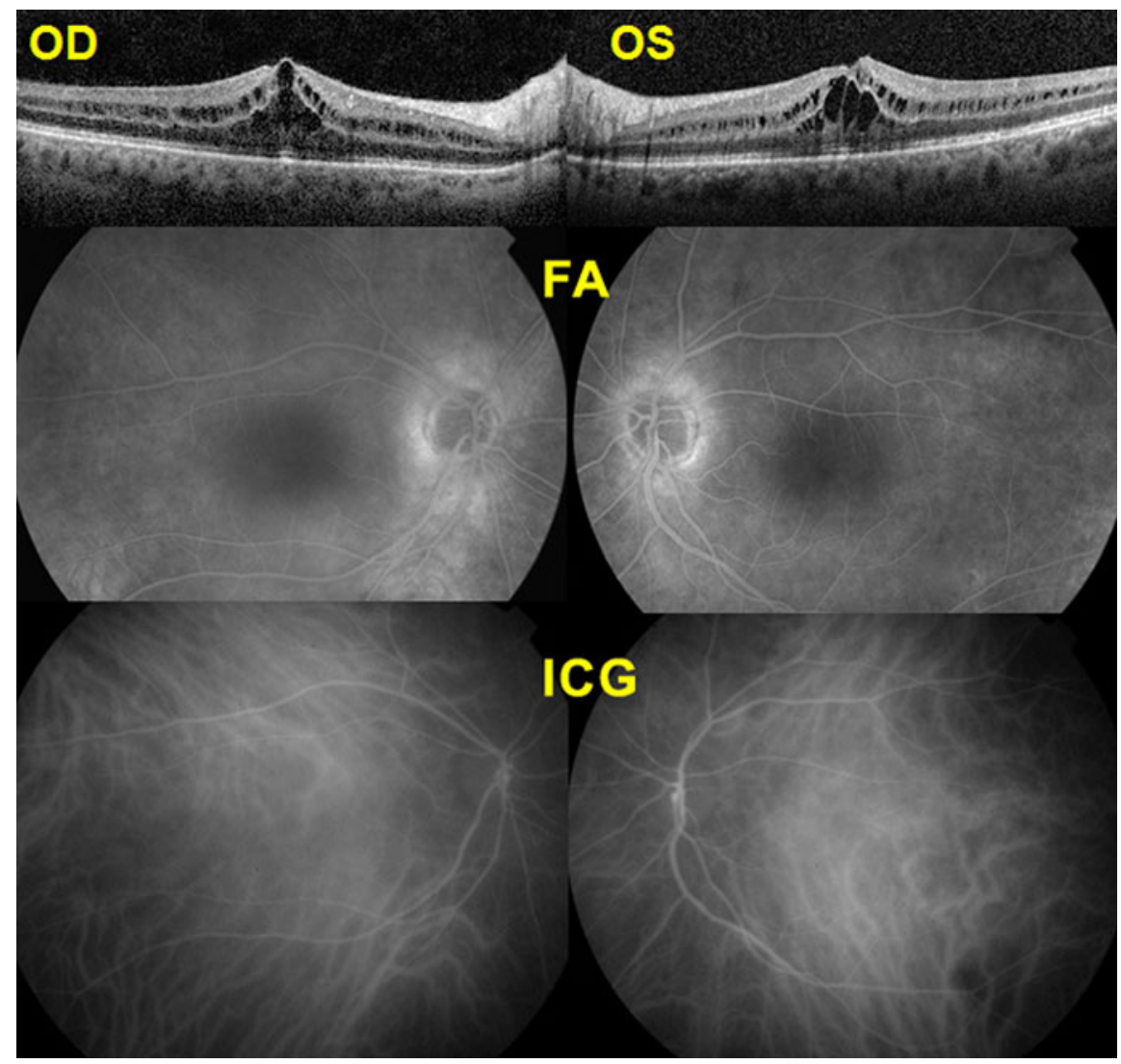

limiting membrane, IS/OS boundary, OS tips, retinal pigment epithelium [RPE]) (Fig. 2). BCVA returned to $0.9 \mathrm{OD}$ and $1.0 \mathrm{OS}$ with progression of the bilateral cataracts. The right cataract was operated 9 months later and the left cataract was operated 14 months later. At no time during the surgical follow-up did the CMO recur even in the immediate post-operative periods. The oncologist reintroduced a taxane treatment from May 3rd, 2011 until October 18th, 2011 using Taxotere ${ }^{\circledR} \quad$ (Docetaxel, cumulative dose $609.14 \mathrm{mg} / \mathrm{m}^{2}$ ) given together with Xeloda ${ }^{\circledR}$ (capecitabine) which did not produce recurrence of CMO.

\section{Hypothesis}

In order to understand the characteristics of TDICMO, we compared the spectral OCT findings of our case to those of an inflammation-induced CMO and to a case of multifocal choroiditis (MFC) to show the difference between attenuation of the four outer OCT bands and their destruction as seen in MFC. The comparison of these three situations is shown in Fig. 3. Figures 3a and $b$ are OCT scans of CMOs of equal thicknesses from our case of TDICMO (3a) and from a case where $\mathrm{CMO}$ is due to inflammation ( $3 \mathrm{~b})$. Figure $3 \mathrm{c}$ is from a case of MFC where the four outer bands are disorganised and partially destroyed. Separation of the retina is at the same level, above the external limiting membrane in both types of oedema. Figure $3 \mathrm{a}$ shows that the four outer bands are present in TDICMO unlike Fig. 3c, from a case of MFC, where they are segmentally destroyed and/or disorganised. It can also be noted that the appearance of the four outer bands are attenuated in the areas of maximal oedema, possibly indicating high-viscosity fluid present in TDICMO. Figure $3 \mathrm{~b}$ shows an inflammation-induced $\mathrm{CMO}$; the structure of the four outer bands is clearly visible without attenuation and comparable to a normal scan (Fig. 3d), probably indicating a less viscous fluid that is not producing a shadow. Consequently it is thought that the density of the CMO fluid 


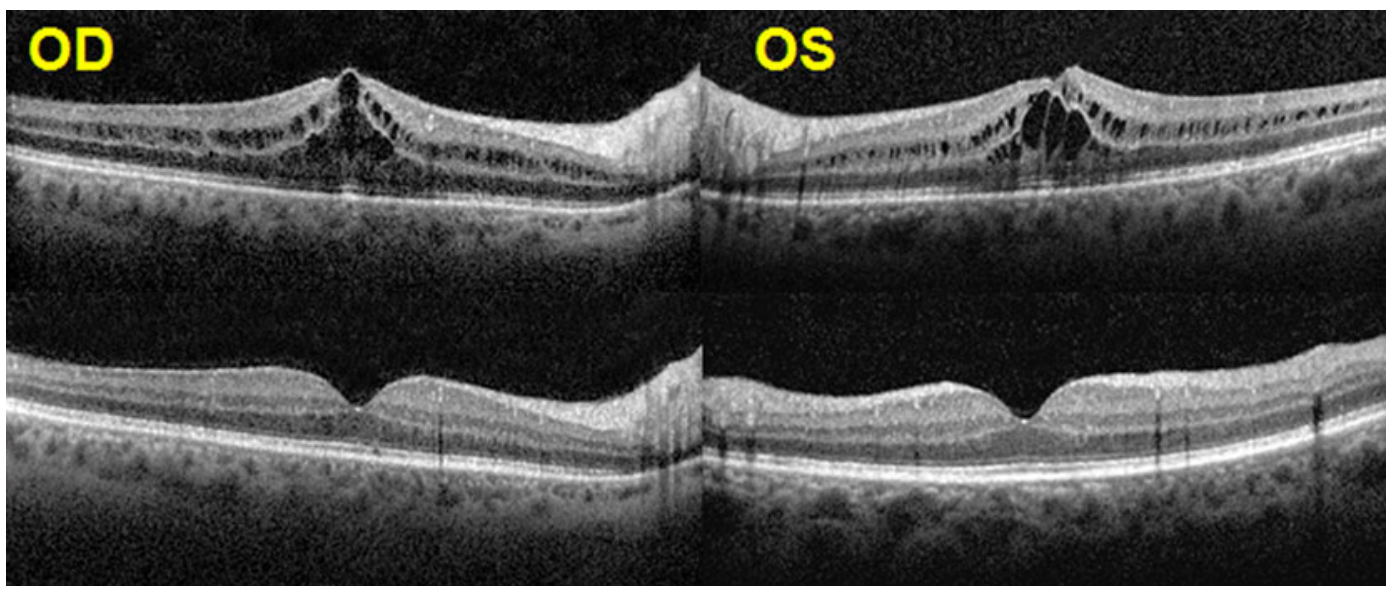

Fig. 2 Top pictures shows bilateral CMO after 10 months of Taxol ${ }^{\circledR}$ treatment; bottom pictures show normal maculas 4 weeks after discontinuation of Taxol ${ }^{\circledR}$ therapy

caused by paclitaxel is higher than the inflammationinduced $\mathrm{CMO}$, as it produces a masking effect on intact outer bands.

Figure $3 \mathrm{c}$ illustrates segmental destruction and/or disorganisation of the four outer bands in a case of MFC which contrasts with the preserved but attenuated outer bands of TDICMO. Taking into account the location of the oedema in the outer retinal layers, the cause of the oedema should be sought in the dysfunction of the RPE $[8,9]$.

\section{Discussion}

Macular oedema or cystoid macular oedema (CMO) is a common cause of vision impairment and is classically demonstrated by FA, showing capillary leakage followed by pooling. CMO without fluorescein leakage is a rare occurrence. Only a few conditions are associated with angiographically silent $\mathrm{CMO}$, and these include some types of retinitis pigmentosa, juvenile X-linked retinoschisis, Goldmann-Favre syndrome and niacin toxicity [10]. The pathogenesis of angiographically silent TDICMO is still unclear but resembles niacin-induced CMO. Several authors explained niacin-induced CMO, which is comparable to TDICMO, as a result of accumulation of intracellular fluid and suggested dysfunction of intracellular metabolism as a leading cause [11, 12].

Investigations performed in our case as well as its clinical evolution give us some sound elements that allow us to put forward a putative but meaningful hypothesis for the occurrence of angiographically silent macular oedema such as TDICMO.

It is clear that the mechanism is not inflammatory. Absence of both fluorescein leakage as well as late hyperfluorescence indicate that there is no inflammatory capillary leakage to explain the presence of subretinal fluid. In support of this are several additional observations: (1) there were no vitreous cells to be seen, (2) there was no subclinical inflammation detected by laser flare photometry which always showed normal values, (3) anti-inflammatory treatment associating steroid and non-steroidal drops had no effect whatsoever on the oedema, and (4) nine and 14 months after the resolution of the bilateral oedemas the right and left cataract were operated, respectively, which failed to produce neither CMO nor OCT thickening of the maculas, showing that the patient's maculas were not prone to develop inflammatory oedema.

The mechanism of TDICMO probably differs from the one of fluid retention syndrome in other parts of the body. In the literature it is known that docetaxel is more likely to be associated with a fluid retention syndrome than paclitaxel as in our case, which can be dose-limiting [13]. The cumulative dose of docetaxel needed for this side-effect is $300-400 \mathrm{mg} / \mathrm{m}^{2}$ and it was increased with additional treatment of corticosteroids to $746 \mathrm{mg} / \mathrm{m}^{2}$ [4].

OCT images show that the plane of separation of the oedema is above the four outer bands. The origin of this type of oedema has to be sought at the level of the RPE. One explanation for the angiographic silence is 
Fig. 3 Difference of the four outer bands in a CMO due to Taxol ${ }^{\circledR}$ showing attenuation of these bands (arrow), b CMO due to inflammation where the four outer bands are well visible (arrow), c MFC showing segmental destruction of the four outer bands (arrow), and $\mathbf{d}$ a normal retinal structure (arrow)
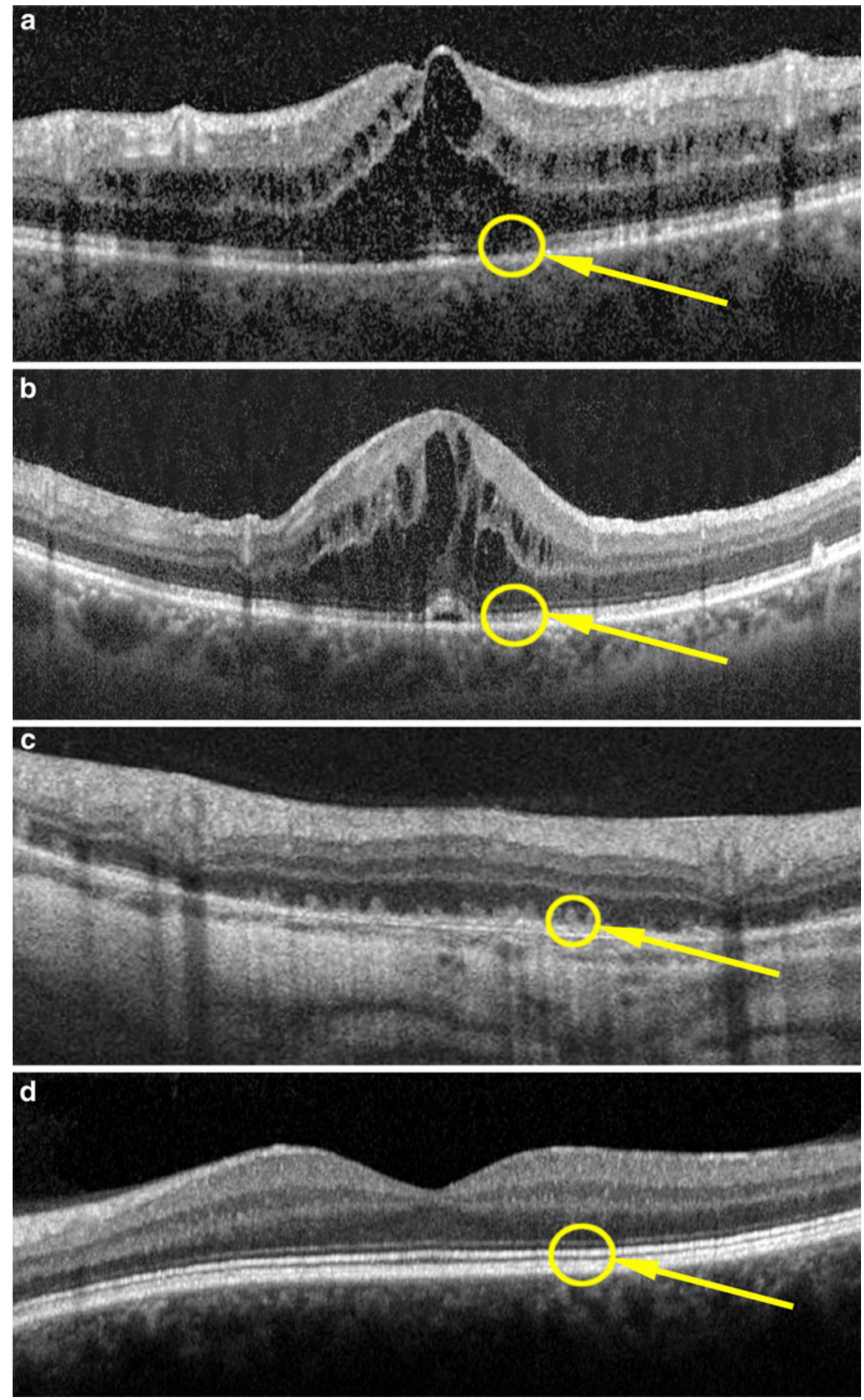

that the origin of the fluid is not from retinal vessels but is probably due to a malfunctioning RPE. Taxol ${ }^{\circledR}$ was shown to disturb the microtubule structure in RPE cells, preventing microtubule disassembly, consequently blocking many microtubule-dependent processes in the RPE [14]. This cytoskeleton-disrupting effect possibly impairs microtubule-dependent transport directed from the apical part of the cell 
towards the base of the RPE cell, possibly allowing proteins to accumulate under the retina and/or disturbing fluid absorption across the RPE [15].

The fluid is not coming directly from the choroid by disruption of tight junctions between RPE cells as there is no leaking point visible neither on FA nor on indocyanine green angiography as seen for example in central serous chorioretinopathy (CSC). Furthermore, no hyperpermeability of choroidal vessels is seen on ICGA as in CSC. The suspected cellular origin of the fluid also explains why none of the circulating fluorescein is getting into these spaces. The suspected elevated viscosity of the exudates could also be an obstacle to diffusion of fluorescein representing an additional reason for the absence of hyperfluorescence. OCT images indicate that the density of the fluid in the oedema is rather high as it constitutes a shadow for the four outer bands in contrast to the fluid in inflammatory-induced CMO where there is no attenuation of this layer. TDICMO is comparable to oedema in $\mathrm{X}$-linked retinoschisis, which is also angiographically silent, and TDICMO can be considered the reversible counterpart of non-reversible hereditary dysfunction of the RPE. Further evidence for the suggested pathophysiological mechanism is that the only effective treatment is discontinuation of taxoid medication.

One remaining question is why one taxane drug, Taxol $^{\circledR}$ (paclitaxel) was toxic to the RPE while another compound Taxotere $^{\circledR}$ (docetaxel) was not. Possibly a certain amount of cumulative dose is necessary to induce the TDICMO and this was not reached by the second compound. In other systemic situations of fluid retention syndrome, the cumulative dose needed to cause side-effects was $300-400 \mathrm{mg} / \mathrm{m}^{2}$ for Taxotere ${ }^{\circledR}$ without corticosteroid treatment and rises to $746 \mathrm{mg} /$ $\mathrm{m}^{2}$ with corticosteroid therapy. Although all three types of taxanes have been shown to be able to induce TDICMO, it is also possible that some patients are at risk for CMO when taking one taxane, but are not prone to develop CMO with another taxane. Further studies are necessary to solve the mystery of angiographically silent macular oedema.

\section{References}

1. Crown J, Leary MO, Ooi WS (2004) Docetaxel and paclitaxel in the treatment of breast cancer: a review of clinical experience. Oncologist 9:24-32

2. Eisner A, Luoh SW (2011) Breast cancer medications and vision: effects of treatments for early-stage disease. Curr Eye Res 36:867-885

3. Teitelbaum BA, Tresley DJ (2003) Cystic maculopathy with normal capillary permeability secondary to docetaxel. Optom Vis Sci 80:277-279

4. Behar A, Lauraine EP, Maurel A, Brun MD, Lagrue G, Chauvin FF, Oulid-Aissa D, Hille D (1997) The pathophysiological mechanism of fluid retention in advanced cancer patients treated with docetaxel, but not receiving corticosteroid comedication. Br J Clin Pharmacol 43: 653-658

5. Semb KA, Aamdal S, Oian P (1998) Capillary protein leak syndrome appears to explain fluid retention in cancer patients who receive docetaxel treatment. J Clin Oncol 16: 3426-3432

6. Smith SV, Matthew BA, Benz S, Brown DM (2008) Cystoid macular edema secondary to albumin-bound paclitaxel therapy. Arch Ophthalmol 126:1605-1606

7. Joshi MM, Garretson BR (2007) Paclitaxel maculopathy. Arch Ophthalmol 125:709-710

8. Bringmann A, Reichenbach A, Wiedemann P (2004) Pathomechanisms of cystoid macular edema. Ophthalmic Res 36:241-249

9. Marmor MF (1999) Mechanisms of fluid accumulation in retinal edema. Doc Ophthalmol 97:239-249

10. Telander DG, Sarraf D (2007) Cystoid macular edema with docetaxel chemotherapy and the fluid retention syndrome. Semin Ophthalmol 22:151-153

11. Karakashian S, Bayliff CD (2001) Niacin-induced cystoid macular edema. CJHP 54:35-36

12. Dajani HM, Lauer AK (2006) Optical coherence tomography findings in niacin maculopathy. Can J Ophthalmol 41:197-200

13. Michaud LB, Valero V, Hortobagyi G (2000) Risks and benefits of taxanes in breast and ovarian cancer. Drug Saf 23:401-428

14. Mitchison TJ (1992) Compare and contrast actin filaments and microtubules. Mol Biol Cell 3:1309-1315

15. Burnside B, Bost-Usinger L (1998) The retinal pigment epithelium cytoskeleton. In: Marmor MF, Wolfensberger TJ (eds) The retinal pigment epithelium. Oxford University Press, New York, pp 41-67 